\title{
Barriers Against Adoption of Electronic Health Record in Italy
}

\author{
Stefano Bonacina ${ }^{1 *}$, Sara Marceglia ${ }^{1,2}$, Francesco Pinciroli ${ }^{1,3}$ \\ ${ }^{1}$ e-healthLAB, Dipartimento di Bioingegneria, Politecnico di Milano, Milan, Italy \\ ${ }^{2}$ Centro Clinico per la Neurostimolazione, le Neurotecnologie ed i Disordini del \\ Movimento, Fondazione IRCCS Ca'Granda Ospedale Maggiore Policlinico, \\ Milan, Italy \\ ${ }^{3}$ Centre for Health Informatics, School of Informatics, City University, London, UK
}

Submitted July 2010. Accepted for publication June 2011.

\begin{abstract}
This work aims to expose the barriers which work against the satisfactory adoption and utilization of Electronic Health Records (EHRs) in Italy. Experts from six operating areas were involved where barriers associated with practical daily use of EHRs might arise. Experts disclosed different barriers in their operating areas: the low interoperability of healthcare system infrastructures in diagnostic services; the lack of systems able to represent complex processes characterized by uncertainties in hospital wards; the unsatisfactory information exchange between heterogeneous healthcare providers in territorial healthcare; the lack of models and guidelines for administration process management; the lack of Health Information engineers who are recognized as professionals in Italian hospitals; the lack of domain vocabularies and ontologies for conceptual integration in clinical communication. Our findings suggest how future solutions must be designed considering the environment of specific areas.
\end{abstract}

Keywords: electronic health record, barriers to EHR adoption, computerized, pragmatic framework, Delphi-like approach

\section{INTRODUCTION}

The electronic health record (EHR) can be defined as a collection of all health-related documents that have been created by different care providers in a digital form. The EHR can also be considered as a planning tool, supporting the care process, from order entry to results management, including decision support [1,2]. Standards regarding the implementation of EHRs underline the need for secure storage, exchange, as well as the

\footnotetext{
* Corresponding Author: Stefano Bonacina. Dipartimento di Bioingegneria, Politecnico di Milano. Piazza Leonardo da Vinci 32, 20133 Milan, Italy. Phone: +39 02 23993303. Fax: +39 0223993360.

E-mail: stefano.bonacina@biomed.polimi.it.

Other authors: sara.marceglia@polimi.it; francesco.pinciroli@polimi.it.
} 
need to understand different user profiles [3-5]. In the term "electronic health record", the use of the word "health" instead of "medical" highlights the fact that it is possible to include personal health data and documents collected independently for a patient, thus introducing the concept of EHR as a persistent longitudinal and potentially multienterprise or multi-national record [3, 5, 6]. Even though the EHR conceptual description and implementation have significantly advanced over the last twenty years, thanks to innovations in Information and Communication Technologies (ICTs), its adoption faces several evolving, long-lasting, and persistent barriers [7-10].

The adoption of an EHR system in Italy should have become widespread after the issuance of the law "DPR 28/12/2000" in December 2000, which states that all Italian public administration institutions must adopt digital documentation (article 50 of the mentioned law). As the Italian Healthcare System is public and regionalized, hospitals and other public healthcare providers were included under this law. Even though the national government guaranteed that the level of funding devoted to the introduction of EHRs was adequate, it did not propose a national unified plan for EHR adoption. At present, EHRs have been adopted in Italy, as well as in many other countries, in hospitals and other health providers even though different institutions use different EHR and Health Information Technology (IT) solutions. The use of EHRs provides some widely acknowledged benefits. One benefit is sustainable checking on data quality, especially when data generation and collection are performed automatically. For instance, data from laboratory devices, or from radiology or biosignal recording systems are automatically obtained and checked even if some parameters are set manually. Another benefit is related to the high storage capability that allows the physical storage of huge amounts of data. The advances in database design and management have led to the implementation of large bio-data warehouses and consequently, the possibility to carry out highly complex and customizable queries on data in a short computational time, producing reliable results. However, different professionals of the healthcare process believe, in the present situation, that the EHR adoption rate and use is still low and unsatisfactory [11].

The aim of this work is to uncover which operating barriers stand against the full and satisfying adoption and utilization of EHRs in the Italian environment. To this end, after carrying out a preliminary literature review, we defined a pragmatic framework representing the main working areas of healthcare where EHR data are generated, used, managed, and shared and where barriers associated with the practical daily use of EHRs might arise. We then involved experts from the operating domains in the framework to obtain a widely agreed list of barriers and possible future solutions for each of the operating domains.

\section{METHODS}

\subsection{Literature Search}

The literature search was first aimed at understanding whether the Italian situation had previously been described and whether there was any framework able to help classify the barriers associated with the practical daily use of EHRs. The secondary aim was to define some "inherited and widely acknowledged barriers" and relate them to the Italian situation. Hence, the literature search was not meant to be a fully comprehensive review 
on EHR adoption in the international scenarios. For this reason, we did not apply any specific search method, such as the meta-narrative method [12- 15].

The search strategy was based on the Pubmed/Medline medical bibliographic database, with search string: < ("electronic health records"[All Fields] OR "electronic medical records"[All Fields] OR "electronic patient records"[All Fields]) AND barriers[tiab] AND 1999[PDAT] : 2009[PDAT] >. The attribute [All Fields] means that the search is performed in all the fields of the Medline record; [tiab] means "title" or "abstract"; [PDAT] means "publication date". The abstracts of the papers obtained were verified based on the following inclusion criteria:

- $\quad$ The paper was published during the period of 1999-2009.

- The length of the paper must be more than one page. The full text of the paper must be available in electronic format.

- The paper contained a specific reference to barriers associated with EHR adoption either in the title or in the abstract.

- The paper did not focus on only one specific component of the EHR (e.g., eprescribing, clinical reminders, clinical decision support systems, clinical practice guideline systems), but was focused on EHR as a whole.

- The paper, if describing the use of specific features of EHRs to improve therapies or diagnosis in specific medical specialty, must address barriers as a main topic.

All the selected articles were fully read to re-assess their pertinence to our inclusion criteria.

In the final set, we searched for articles relating to the Italian situations. We then looked for articles presenting comprehensive operating frameworks of all the working areas of healthcare where barriers might arise. Finally, from a textual and narrative analysis of the articles selected, we extracted a list of barriers inherited from the past and agreed on in the international scenarios.

\subsection{Barrier Validation and Ranking}

To address barriers, we followed an approach to take the opinion of experts in the field into account [16]. We followed a modified version of the Delphi Method [17]. This is mainly a forecasting method based on the administration of a questionnaire on a selected topic to a panel of experts in two or more rounds. The process concludes after meeting a pre-defined stop criterion that could be the stability of the results or the achievement of a consensus between the experts for instance. A "facilitator" coordinates the responses of the experts and provides a summary of the responses and their motivations, thus encouraging all the experts to re-think about their opinions in the light of the judgments expressed by the others. Pooling the opinions of a group of specialists produces a consensus that is more reliable and more widely accepted than coming from a single person, even if that person is highly skilled in the field [16].

We (the authors) played the role of facilitators. On the basis of the results of our preliminary literature search, we designed a pragmatic framework that considered the working areas of healthcare where data are generated, used, managed, and shared in digital form (Figure 1, see Results). We then put together a list of 34 possible barriers against the adoption and utilization of EHR in Italian scenarios. Each of these 34 
barriers could belong to one or more of the areas making up the pragmatic framework. We used this list as the starting point for a Delphi-like approach.

Experts were requested to evaluate the list, with the liberty of adding new items or deleting existing items, and then to score each barrier on a $1-5$ scale $(1=$ not considered as a barrier; $5=$ very important barrier). The selection of experts is detailed in section 2.3.

First, we used the answers from the experts to validate the list of 34 candidate barriers. The first element for validation was the inclusion of new barriers or the exclusion of proposed barriers by the experts. The scores received by each barrier were then averaged across all the experts. The barriers with an average score below 2 were excluded from the list. We then considered the low-scoring barriers (between 2 and 2.5) and high-scoring barriers (>3.5). A low score could either mean that the barrier was indeed of low importance or that the expert did not consider it important (for instance, because the barrier was out of the expert's domain). Conversely, a high score could either mean that the barrier was really difficult to manage or that the barrier was perceived as very important but, in reality, could be overcome quite easily. In addition, we performed a non-parametric Friedman ANOVA to test whether the average scores of each barrier were significantly different. To perform a post-hoc analysis, we conducted paired U-tests compared to a statistic based upon the Studentized range $(\mathrm{p}<0.05)$. A barrier was considered as significantly high or low had it a significantly different score compared to most of the other barriers.

To test whether the experts in different areas had a different perception regarding a single barrier, we re-evaluated the scores received by all barriers grouping experts per area. Each of the 34 barriers we listed could relate to one or more of the six areas we considered (see Table 1). For instance, the lack of specific health IT courses in medical curricula is a barrier relating to the area of "Education", whereas the complexity of medical knowledge representation (e.g., taxonomies, ontologies) mostly relates to the "Clinical Communication" area. To avoid biases in the experts' evaluations, the list was presented to them without grouping the items according to area, in the order shown in Table 1. Hence, experts scored individual barriers without knowing whether they were attributed to their area of expertise. Barriers were categorized in terms of low-scoring $(<2)$ and high-scoring $(>3.5)$. To conclude the first round of our modified Delphi method, we gave the results of this analysis to each expert. As a second round, we organized a national event ("Barriere all'adozione della cartella clinica informatizzata", available at www.sanitadigitale.polimi.it) where all the experts were invited to a roundtable discussion concerning their areas of expertise. The event consisted of six roundtables (one for each area of the framework) with the participation of four to eight experts. Each roundtable was coordinated by either a journalist or a representative of the Italian Government (from the Ministry of Health). The main goal of the roundtable discussion was to identify widely accepted opinions among the experts and to justify the scores received by the barriers. The roundtables were videotaped and the materials presented were collected. From the videotapes and the presentations, we extracted the perceptions of the experts regarding the barriers in their specific areas in order to obtain a shared opinion on barriers against the adoption and use of EHR in each operating area. 


\subsection{Expert Selection}

We selected four to eight experts for each area defined in the pragmatic framework. The expertise of these experts was proved by their position in scientific societies, in leading companies, or in hospitals with a recognized wide experience in EHR use, on an Italian level. They must have not only academic or theoretic experience in their area but also a practical experience. Also, they should have a high level of IT skills. Selected experts represented all the possible stakeholders in each area, including clinicians, technicians, service providers, and patients/consumers.

\section{RESULTS}

\subsection{Literature Search}

We found 111 papers using the method described in section 2.1. By screening based on our inclusion criteria, we selected 66 papers. After full text review, 50 papers were selected.

The situation of EHR implementation in Italy was not described in any of the papers selected, nor did any of them describe an operating framework representing the main working areas of healthcare where EHR data are generated, used, managed, and shared and where barriers associated with practical daily use of EHRs could arise.

From the textual analysis and narrative interpretation of the selected papers, we found the following barriers against the adoption of EHRs:

- The need for appropriate education and skills in medical informatics, health informatics or biomedical informatics $[18,22-26,37,38,40,41,44,46,48$ $50,56,62,64]$.

- Consumers' and physicians' concerns about the privacy and security of electronic health information $[18,19,23-25,26,39,41,46,47,49-51,56,59$, $60,66]$.

- Economical and financial factors, including misalignment of incentives, limited demonstrated value of EHRs in practice, limited purchasing power among providers, the volatile market, the high costs of EHRs, and the perceived lack of financial return of the investment in EHR [18, 20, 23, 24, 28$33,39-45,48-53,54,56,59,61,62,67]$

- Lack of time required to switch from paper-based health records to EHR systems [18, 24,27, 48, 53, 57]

- The delay in standard adoption causing inconsistent viability of EHR products and companies [21, 24, 34, 43, 45, 51, 63].

- The large number of EHR standards under development resulting in a limited interoperability among systems in different healthcare institutions using incompatible EHR standards [18, 20, 24, 30, 32, 34, 36, 41, 42, 44, 45, 50, 56, $57,59,61,65]$.

- The loss of autonomy and the workflow disruption through EHR adoption [29, $38,44,46,47,49,54,67]$.

- Physicians' acceptance and satisfaction with the system [18, 22, 24, 26, 28, 30, 32, 33, 37, 44, 51, 58, 64, 68]: reasons why EHR systems are not preferred during patient visits include loss of eye contact with patient, inability to type quickly, and preference to write long prose notes. 
- The technical and logistic challenges involved in installing, maintaining, and updating EHR systems could become a source of anxiety and aggravation to staff $[18,23,24,28,31,34,39,41,55,62,65]$.

- Vendors' inability to deliver satisfactory products or services $[34,36,39,46$, $58,67]$.

We considered this list as a set of inherited and generally recognized barriers which will be incorporated into a framework representing the operating areas where EHR data are generated, used, managed, and shared, as described below.

\subsection{The Pragmatic Framework}

Based on our experience in the Italian health systems, we designed a pragmatic framework that represented the working areas of healthcare where data are digitally generated, used, managed, and shared.

Hospitals are healthcare providers, generating and using health-related data and documents, connected to other healthcare providers in a certain geographic area, which is a region in Italy in our case. Software and communication providers design and develop healthcare applications that are used by health personnel. All these stakeholders define the Territorial Healthcare area. The area of Education is not directly involved in healthcare processes but it is needed to provide trained professionals: people managing and using EHR data should be trained to ensure proper knowledge. The hospital includes different elements involved in patient care. IT infrastructures, including local data warehouses and reference knowledge bases, support the clinician (who is the clinical decision maker) in order to provide care to the patient. Data included in the hospital data warehouses are mainly generated in the area of Diagnostic Services. Diagnostic Services also use reference databanks and interact with patients. In Hospital Wards, data from hospital data warehouses, reference databanks, and patients are used to manage the clinical decision making process. The Management and Organization area also interacts with all the clinical departments. Data representation and communication are needed to share data between all these areas.

The above consideration led to the identification of the following six areas where we investigated the barriers to EHR adoption:

1. Diagnostic Services. Diagnostic Services, mainly the pathology and the radiology services, are the areas in the hospital environment where data are generated by medical instrumentation. Diagnostic Services are characterized by an information flow in which a large amount of digital patient data are generated and stored within the department, while a small part is shared across different hospital units through network connections. The usual information workflow starts from a list of requested examinations coming from the hospital's booking system, other departments within the same hospital, or from other hospitals. The list of requested examinations entails scheduling of the laboratory activities. After an examination procedure is completed, a report is generated and provided to the patient and/or the party who requested the examination. Finally, the report is archived. In Italy, at present, most examination reports are produced in digital format; however, a printed paper 
report is usually also given to the patient. In this scenario, barriers could arise from interoperability between machines, standard adoption, data transmission, and privacy and security issues.

2. Hospital Wards. The most valuable use of hospital data occurs at the patient's bedside, mainly for diagnosing and caring, decision making, as well as monitoring a patient's status. Data are usually the inputs from a humanimplemented and complex process for patient diagnosis, and EHR is part of the implementation of this complex and non-deterministic process. In fact, despite the diagnostic values of signs and symptoms, their multiple interpretations and interactions lead to a process characterized by uncertainties. EHR systems would become fundamental supporting tools when characterized by data quality ascertainment, ad-hoc lexicons management, statistical reporting, targeted research, and workflow processes for quality control.

3. Territorial Healthcare. As patients frequently need to change healthcare provider (e.g., in order to be cared by the desired physicians), EHR data transmission is an issue when considering the whole healthcare geographic area. This operating area is also characterized by the booking systems that could be either self-managed or managed through healthcare institution call centers. These systems face a problem of the level of patient's health literacy needed for booking the examination. Another problem is the implementation of an adequate authorizing system which protects patient's rights in a certain geographical area.

4. Management and Organization. Resource and expenditure management can be facilitated by IT in any field. In those countries where healthcare is a social right, the costs should be kept under control. Administrative data are needed to evaluate costs, revenues, and/or reimbursements, that are for the most part provided by the government of the region in Italy. Such data are usually complementary and not always in line with the clinical data considered in the previous three areas. An example of such misalignment is the fact that vital statistics are collected every time a patient is admitted to a ward without ensuring patient's unique identification.

5. Education. An EHR data user should be a well educated professional, kept updated through appropriate continuing education programs. Physicians and general practitioners may not be familiar with "bits and bytes" if they are not properly introduced to the importance of IT and how IT might enhance healthcare delivery. Important tools such as Unified Medical Language System (UMLS), Systematized Nomenclature of MEDicine (SNOMED), and others are still not widely covered in medical curricula. Educational issues are also on the side of health system developers, particularly affecting medical computer scientists and biomedical engineers.

6. Clinical Communication. The communication of medical and health-related knowledge becomes an issue when the same data is shared between heterogeneous user profiles having different areas of expertise and basic lexicons. The evolution of medical knowledge has outpaced updating of 
medical dictionaries, standards, and lexicons. Correct clinical communication enhances usefulness, clarity, non-redundancy, essentiality, completeness, and accessibility of EHR data, thus decreasing clinical risk.

\subsection{Barrier List Validation}

The average results of the barrier questionnaire are exhibited in Table 1, with more statistical details presented in Figure 1. The mean scores ranged from 1 (not a barrier) to 5 (very important barrier). The first result was that none of the experts added or excluded any barriers. Secondly, none of the proposed barriers received an average score below 2 . Hence, this 34 -item list was considered as a complete reference by all the experts.

Table 1. List of the 34 barriers submitted to the experts for evaluation and scoring. A1=Diagnostic Services; A2=Hospital Wards; A3=Territorial Healthcare; A4= Management and Organization; A5= Education; A6= Clinical Communication.

\begin{tabular}{|c|c|c|c|}
\hline & BARRIER & $\begin{array}{l}\text { MEAN } \\
\text { SCORE }\end{array}$ & $\begin{array}{c}\text { AREA/S TO } \\
\text { WHICH THE } \\
\text { BARRIER } \\
\text { BELONGS }\end{array}$ \\
\hline 1 & The complex informatics taxonomy of medical knowledge. & 2.94 & $\mathrm{~A} 2, \mathrm{~A} 5, \mathrm{~A} 6$ \\
\hline 2 & $\begin{array}{l}\text { The inability of informatics to provide easy conceptual } \\
\text { integration. }\end{array}$ & 3.25 & A2, A6 \\
\hline 3 & $\begin{array}{l}\text { The inability of informatics to contextualize clinical data in } \\
\text { its scenario. }\end{array}$ & 3.40 & $\mathrm{~A} 2, \mathrm{~A} 6$ \\
\hline 4 & $\begin{array}{l}\text { The short lifetime of the information contained in clinical } \\
\text { data. }\end{array}$ & 2.33 & $\mathrm{~A} 2, \mathrm{~A} 6$ \\
\hline 5 & $\begin{array}{l}\text { The difficulty in balancing the synthetic representation } \\
\text { needed for easy everyday use of clinical information and } \\
\text { the deeply detailed representation needed in digital systems } \\
\text { for knowledge management. }\end{array}$ & 3.20 & $\mathrm{~A} 2, \mathrm{~A} 6$ \\
\hline 6 & $\begin{array}{l}\text { The lack of an easy and appropriate use of electronic } \\
\text { medical dictionaries. }\end{array}$ & 2.56 & $\mathrm{~A} 1, \mathrm{~A} 2, \mathrm{~A} 6$ \\
\hline 7 & $\begin{array}{l}\text { The lack of an easy and appropriate use of operative and } \\
\text { scientific bibliography databases. }\end{array}$ & 2.33 & A5, A6 \\
\hline 8 & $\begin{array}{l}\text { The lack of an easy and appropriate use of biosignal } \\
\text { databases. }\end{array}$ & 2.17 & A1 \\
\hline 9 & $\begin{array}{l}\text { The lack of an easy and appropriate use of bioimage } \\
\text { databases. }\end{array}$ & 2.28 & A1 \\
\hline 10 & The lack of an easy and appropriate use of guidelines. & 3.11 & $\mathrm{~A} 2, \mathrm{~A} 6$ \\
\hline 11 & $\begin{array}{l}\text { The lack of high fidelity networks able to manage } \\
\text { multimedia healthcare data. }\end{array}$ & 2.75 & $\mathrm{~A} 1, \mathrm{~A} 3$ \\
\hline 12 & $\begin{array}{l}\text { The low level of use of digital resources by clinicians for } \\
\text { scientific purposes even if the digital resources are } \\
\text { powerful and useful. }\end{array}$ & 3.16 & A5 \\
\hline 13 & $\begin{array}{l}\text { The long time needed to finalize standards compared to the } \\
\text { fast evolution of IT. }\end{array}$ & 3.30 & A1 \\
\hline
\end{tabular}




\begin{tabular}{|c|c|c|c|}
\hline 14 & $\begin{array}{l}\text { The inability of the clinical or administrative customer to } \\
\text { supply the full software specifications to the industrial } \\
\text { provider. }\end{array}$ & 3.65 & $\mathrm{~A} 1, \mathrm{~A} 2, \mathrm{~A} 3, \mathrm{~A} 4$ \\
\hline 15 & $\begin{array}{l}\text { The possible problems related to responsibility for data and } \\
\text { their possible future misuse. }\end{array}$ & 3.21 & $\mathrm{~A} 1, \mathrm{~A} 4$ \\
\hline 16 & The exponential increase of digitally generated data. & 2.85 & A1 \\
\hline 17 & $\begin{array}{l}\text { The lack of digital systems supporting the management of } \\
\text { complex care processes (i.e., more than one healthcare } \\
\text { operator caring for a single patient). }\end{array}$ & 3.55 & $\mathrm{~A} 2, \mathrm{~A} 4$ \\
\hline 18 & The high expectations of patients on privacy issues. & 2.45 & $\mathrm{~A} 3, \mathrm{~A} 4$ \\
\hline 19 & $\begin{array}{l}\text { The need of IT infrastructures for the use of medical } \\
\text { guidelines. }\end{array}$ & 2.95 & A2 \\
\hline 20 & The lack of Biomedical Engineers in hospitals. & 3.37 & $\mathrm{~A} 4, \mathrm{~A} 5$ \\
\hline 21 & $\begin{array}{l}\text { The lack of specific health IT educational paths in medical } \\
\text { schools. }\end{array}$ & 3.70 & A5 \\
\hline 22 & $\begin{array}{l}\text { The lack of Continuing Medical Education (CME) paths } \\
\text { specific for health IT. }\end{array}$ & 2.95 & A5 \\
\hline 23 & The great difficulty in developing scalable systems. & 3.53 & $\mathrm{~A} 1, \mathrm{~A} 3$ \\
\hline 24 & Forecasting the future adoption of new laws. & 2.40 & $\mathrm{~A} 3, \mathrm{~A} 4$ \\
\hline 25 & The unsatisfactory application of privacy legislation. & 2.47 & A3, A4 \\
\hline 26 & The lack of control on prescriptions and services provided. & 2.33 & $\mathrm{~A} 3, \mathrm{~A} 4$ \\
\hline 27 & $\begin{array}{l}\text { The lack of software designed and developed following a } \\
\text { widespread industrial view. }\end{array}$ & 3.11 & $\mathrm{~A} 1, \mathrm{~A} 2$ \\
\hline 28 & $\begin{array}{l}\text { The lack of management guidelines in hospitals and local } \\
\text { public healthcare providers ("Azienda Sanitaria Locale - } \\
\text { ASL", in Italian). }\end{array}$ & 3.61 & A3, A4 \\
\hline 29 & $\begin{array}{l}\text { Process management exclusively conducted through a top- } \\
\text { down approach. }\end{array}$ & 4.06 & A4 \\
\hline 30 & $\begin{array}{l}\text { The low skills of national administration in project } \\
\text { activities. }\end{array}$ & 4.00 & A3, A4 \\
\hline 31 & $\begin{array}{l}\text { The lack of automated quality control on the generated } \\
\text { data. }\end{array}$ & 3.35 & A1 \\
\hline 32 & The inability to store huge amounts of data. & 2.00 & A1 \\
\hline 33 & $\begin{array}{l}\text { The low level of reliability and flexibility of queries in } \\
\text { medical knowledge databases. }\end{array}$ & 2.85 & A2, A6 \\
\hline 34 & The low execution speed of CPU instructions. & 2.56 & $\mathrm{~A} 1, \mathrm{~A} 6$ \\
\hline
\end{tabular}

Nine of the 34 barriers were scored in the lower range (between 2.0 and 2.5), and seven in the higher range (above 3.5). Among them, some barriers significantly differed from the others (Figure 1). In particular, the lowest score was attributed to "the inability to store huge amounts of data" (barrier 32). Some barriers regarding the management and organization were perceived by experts as surmountable in the near future (barriers $26,24,25)$. On the other hand, the fact that health-process management is exclusively conducted through a top-down approach (barrier 29), and that the Public Administration is not qualified to design and manage projects (barrier 30) were considered as high priority. IT education of medical professionals was a major concern as well (barrier 21). From a software design point of view, experts agreed on the general lack of clear user requirements (barrier 14). 


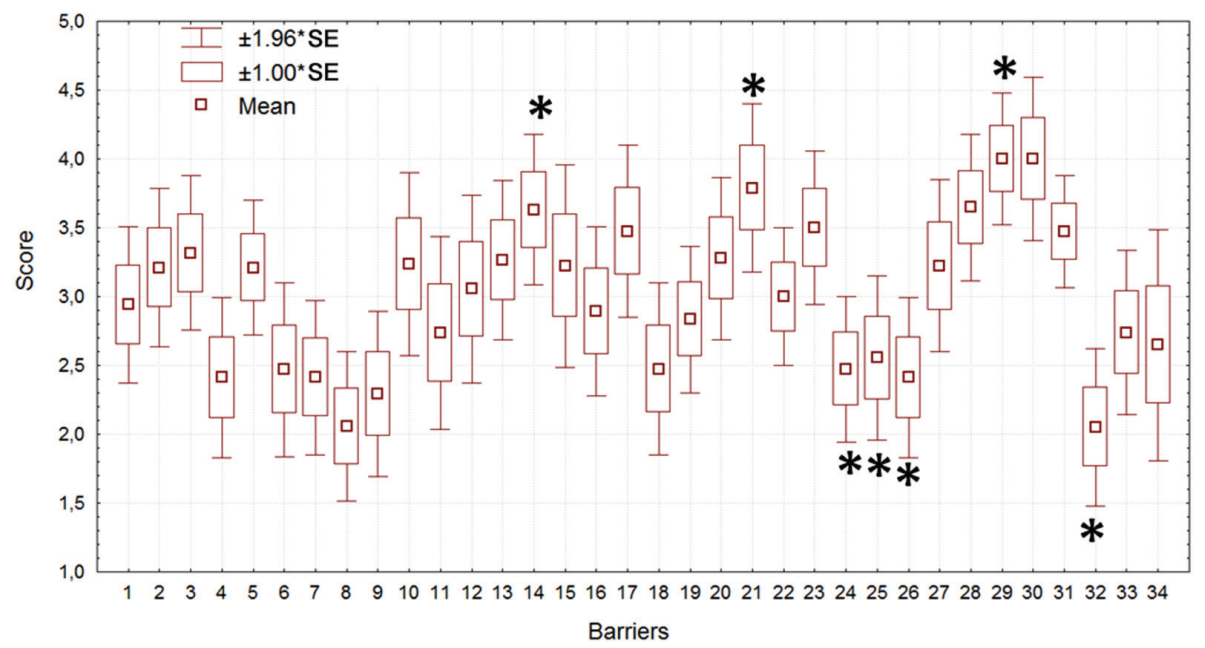

Figure 1. Scores of barriers. The mean, the standard error (SE) and the confidence interval of $1.96 * \mathrm{SE}$ are presented. Asterisks $(*)$ indicate barriers significantly different from the others in a post-hoc U-test $(\mathrm{p}<0.05)$.

\subsection{Barriers Related to the Areas in the Pragmatic Framework}

Results classified per area and across areas are shown in Table 2. The next paragraph summarizes some basic observations based on Table 2. Other debatable observations will be presented in the Discussion.

Diagnostic Services - The experts in the Diagnostic Services area from the radiology unit and biological laboratory scored barriers related to software flexibility as the most important ones (barriers 14, 23, and 31). A second important point pertained to the digital signature of reports, documentation access and responsibility (barrier 15). Conversely, they did not consider technological problems such as storage capability and processor speed as relevant (barriers 32 and 34). In evaluating barriers from other areas, particular attention was paid to Education (barriers 21 and 22). The experts also perceived a high responsibility of the Management and Organization area (barriers 17, 28, 29, and 30).

Hospital Wards - The experts in the Hospital Wards area possess cardiology and oncology specialties. Within their domain, they rank the lack of systems which are able to manage complex processes (barriers 5, 17, and 19) as the most important barriers. On the other hand, the lack of a computerized conceptual integration was not perceived as a barrier (barrier 2). Across other areas, again the lack of health IT education in medical curricula was underlined as important (barrier 21), together with management inabilities of the administrative personnel (barriers 29 and 30). No barriers from the Clinical Communication area were highlighted.

Territorial Healthcare - The experts in this area represented three operational points of view: the booking systems, the patients/citizens, and the companies providing IT solutions. In this area, barriers were related to the systems devoted to the 
management of healthcare in a geographic area with multiple types of users (barriers 14, 23, 28, and 30). They also considered privacy and security issues (barriers 18 and 25) important.

Table 2. Results of barrier scores grouped per area. The columns contain the six areas and barriers therein. The rows are defined as participating experts in each area. In the diagonal cells (shaded), the numbers of the barriers in a certain area (column) and scored by experts in the same area (row) are presented. Each diagonal cell is divided into two sub-cells. The light grey sub-cell contains barriers scoring $>3.5$ whereas the dark grey sub-cell contains barriers scoring < 2.0. In the other (non-diagonal) cells, the number(s) of the barriers in a certain area (column) and scoring $>3.5$ by experts from other expertise areas (rows) are presented.

\begin{tabular}{|c|c|c|c|c|c|c|}
\hline \multirow[b]{2}{*}{$\begin{array}{l}\text { Experts } \\
\text { Per Area }\end{array}$} & $\begin{array}{l}\text { DIAGNOSTIC } \\
\text { SERVICES }\end{array}$ & $\begin{array}{c}\text { HOSPITAL } \\
\text { WARDS }\end{array}$ & $\begin{array}{l}\text { TERRITORIAL } \\
\text { HEALTHCARE }\end{array}$ & $\begin{array}{c}\text { MANAGEMENT } \\
\text { AND ORGANIZATION }\end{array}$ & EDUCATION & $\begin{array}{c}\text { CLINICAL } \\
\text { COMMUNICATION }\end{array}$ \\
\hline & $\begin{array}{c}\text { BARRIER \# } \\
6,8,9,11,13,14,15, \\
16,23,27,31,32,34\end{array}$ & $\begin{array}{c}\text { BARRIER \# } \\
1,2,3,4,5,10 \\
14,17,18,27,33\end{array}$ & $\begin{array}{c}\text { BARRIER \# } \\
11,14,18,23,24, \\
25,26,28,30\end{array}$ & $\begin{array}{c}\text { BARRIER \# } \\
14,15,17,18,20,24 \\
25,26,28,29,30\end{array}$ & $\begin{array}{c}\text { BARRIER \# } \\
1,7,12,20,21,22\end{array}$ & $\begin{array}{c}\text { BARRIER \# } \\
1,2,34,5,6,7, \\
10,33,34\end{array}$ \\
\hline \multirow{2}{*}{$\begin{array}{l}\text { DIAGNOSTIC } \\
\text { SERVICES }\end{array}$} & $14,15,23,31$ & \multirow[b]{2}{*}{17} & \multirow{2}{*}{28,30} & \multirow{2}{*}{$17,28,29,30$} & \multirow{2}{*}{21,22} & \\
\hline & $8,9,34,32$ & & & & & \\
\hline \multirow{2}{*}{$\begin{array}{l}\text { HOSPITAL } \\
\text { WARDS }\end{array}$} & \multirow[t]{2}{*}{11} & $5,17,19$ & \multirow[t]{2}{*}{11,30} & \multirow[t]{2}{*}{29,30} & \multirow[t]{2}{*}{21} & \\
\hline & & 2 & & & & \\
\hline \multirow{2}{*}{$\begin{array}{l}\text { TERRITORIAL } \\
\text { HEALTHCARE }\end{array}$} & \multirow{2}{*}{$13,15,31$} & \multirow{2}{*}{$2,3,17$} & $14,23,18,28,25,30$ & \multirow{2}{*}{$15,17,29$} & \multirow{2}{*}{$12,20,21$} & \multirow{2}{*}{2,3} \\
\hline & & & 24 & & & \\
\hline \multirow{2}{*}{$\begin{array}{l}\text { MANAGEMENT } \\
\text { AND } \\
\text { ORGANIZATION }\end{array}$} & \multirow{2}{*}{2,23} & & \multirow{2}{*}{23} & $30,15,28,29$ & \multirow{2}{*}{1,21} & \multirow{2}{*}{1,2} \\
\hline & & & & 17 & & \\
\hline EDUCATION & $14,16,31$ & 5,14 & $14,28,30$ & $28.29,30$ & 20 & 5,16 \\
\hline \multirow{2}{*}{$\begin{array}{l}\text { CLINICAL } \\
\text { COMMUNICATION }\end{array}$} & \multirow{2}{*}{$13,14,15,23,27$} & \multirow{2}{*}{$14,17,27$} & \multirow{2}{*}{$14,23,28,30$} & \multirow{2}{*}{$15,17,28,30$} & \multirow{2}{*}{12,21} & $2,3,5$ \\
\hline & & & & & & $1,4,7$ \\
\hline
\end{tabular}

Management and Organization - Major barriers in the Management and Organization area were the lack of effective models and guidelines for process management (barriers 28, 29, and 30). The experts in this area expressed concerns about responsibilities for digital data especially with regard to future misuse (barrier 15). Like the experts from other areas, they also highlighted barriers in education (barriers 1 and 21).

Education - The experts in Education considered the lack of Biomedical/Healthcare Engineers as a recognized profession in hospitals (barrier 20) more important than any other barrier in their area. On the other hand, these experts highlighted many barriers in all of the other operating areas, in particular concerning data management (barriers 14, 16 and 31 in Diagnostic Services), software specifications (barrier 14 in Hospital Wards), management guidelines (barrier 28 in Territorial Healthcare), manager skills (barriers 29 and 30 in Management and Organization), and medical knowledge representation (barrier 5 in Clinical Communication).

Clinical Communication - The experts in this area perceived data representation and integration as the primary barriers in the area (barriers 2, 3, and 5), whereas the 
complex definition of taxonomies, the time-dependency of the meaning of clinical data, and the use of bibliographic databases were considered as more sustainable (barriers 1, 4, and 7). They considered the development of software designed on the basis of real clinical needs and standards (barriers 13, 14, 15, 17, 23, and 27), the lack of management guidelines (barriers 28 and 30), and education (barriers 12 and 21) of great importance.

\section{DISCUSSION}

In this work, we proposed a pragmatic framework representing the operating healthcare areas where barriers stand against the full and satisfactory adoption and use of EHRs in the Italian experience. We developed a list of 34 barriers validated by a panel made up of experts in the six areas defined in the pragmatic framework, namely Diagnostic Services, Hospital Wards, Territorial Healthcare, Management and Organization, Education, and Clinical Communication. The experts from different areas underlined different barriers, thus suggesting that future solutions must be designed considering the environment of the specific operating area. In particular, we found that in Diagnostic Services, the highlighted barriers were related to the low flexibility and interoperability of healthcare system infrastructures; in Hospital Wards, major barriers were related to the lack of systems capable of representing complex processes characterized by uncertainties; in Territorial Healthcare, experts underlined the unsatisfactory information exchange among different healthcare providers, especially in personalized health record; in Management and Organization, the most important barrier was the lack of models and guidelines for administration process management; in Education, the major problem is the lack of Biomedical/Healthcare engineers recognized as professionals in Italian hospitals; in Clinical Communication, the lack of domain vocabularies and ontologies for conceptual integration was highlighted.

The preliminary literature search confirmed that neither the EHR adoption in Italy had been previously analyzed, nor had these barriers ever been considered in a pragmatic framework for EHR data. Even though our pragmatic framework is based on a vision that seemed quite natural, it has never been described in literature to the best of our knowledge. However, literature provides full and comprehensive reviews on barriers to EHR adoption, which can be summed up with the need for appropriate education in health and medical informatics, economical and financial aspects, delays in standard adoption, limited interoperability between systems in different healthcare institutions, physicians' slow acceptance and users' dissatisfaction with the system, the long time needed to progress from paper-based to digital health records, loss of autonomy and workflow disruption of the medical personnel, technical and logistic challenges involved in installation, maintaining, and updating EHR systems, consumers' and physicians' concerns about privacy and the security of electronic health information, and vendors' inability to deliver satisfactory products or services [18-69].

The experts neither added nor excluded any barrier on the list we provided, even though they were specifically requested to do so. During the roundtable discussion, none of the experts added any barriers which were different from the 34 items already on the list. However, a serious limitation of this approach was that asking experts' opinion after showing them our set of 34 barriers could have created an inhibiting 
effect. Our analysis contextualized specific barriers to the healthcare operating domains where digital data are generated, used, managed, and shared. This led us to consider barriers and solutions in the environment of the specific area, making a more in- depth interpretation of the findings possible. In fact, some barriers received quite different average scores by all the experts than that by the experts of a particular area. For instance, privacy and security issues (barriers 18 and 25) received low score by all experts because in Italy, there are strong policies for patient data treatment; however, the same issue was ranked of major importance by experts in Territorial Healthcare representing consumers' point of view.

In the Diagnostic Service area, our results suggest that the goal for the near future is to improve system interoperability even though standards such as DICOM and SNOMED are available. In fact, experts underlined the problem of low interoperability of present systems, considering that a great part of the data generated could be transmitted outside the boundaries of a single hospital to other hospitals or to general practitioners (GPs). At present, to overcome such lack of system flexibility, a CD-ROM containing bioimages and medical reports is created and given to the patient as an examination report. However, the use of such media by GPs and family physicians requires not only the computer equipment suitable for visualization but also computer skills and literacy to manage bioimages generated from different systems. Improved system interoperability would allow for easy transmission of data generated within the Diagnostic Services, thus decreasing time and responsibility for the patient. On the other hand, in this area, experts considered technological barriers such as lack of storage capacity as "old", given the fact that the current technology allows storing information in petabytes.

Hospital Wards represent the patient's bedside, where data are "used", wherever and whenever generated. Our analysis disclosed that the major need is for the development of more reliable systems capable of representing and integrating complex data, and managing processes based on clinical practice guidelines, thus decreasing risks of medical errors. In fact, in this area, the integration of clinical data in complex processes, where uncertainties are greater than certainties, is inevitable to perform accurate diagnoses. Cases of cardiology and oncology were selected to represent hospital wards in the present study. Despite some differences, these two specialties share the same need for a long term follow-up during which the patient needs to be monitored. Even though stand-alone systems for patient management exist, the long follow-up time required implies that a patient might be referred to centers other than the one which initially diagnosed the disease. With stand-alone systems that cannot share data in electronic format, in order to sustain continuity of care, the patient is forced to bring with him/her a printed copy of the clinical record of preceding treatments or exams. The introduction of systems where the medical history of patients can be followed across different centers would decrease both the time needed to perform an accurate diagnosis and the risk of errors.

When considering Territorial Healthcare, interoperability-related barriers prevent efficacious information exchange between heterogeneous providers. As a future solution, the experts proposed life-long patient records adopting time-oriented or problem-oriented models. From the consumer's point of view, the focus was on privacy issues, even though relative laws already exist. 
In Management and Organization, the introduction of process-based modeling tools for hospital administration was considered as a possible solution to cut costs. A positive example was provided by the San Raffaele Hospital in Milan, where a renewed hospital information system was developed through a process-based approach that included a unified and real-time view on important information accessible ubiquitously in the hospital and integration among different departments and between front- and backoffice services. It also allowed for a focus of the institutional resources on the most critical activities.

In a long-term perspective, Educational program enhancement aimed at reducing the gap between the "users" and the "developers" of health information systems could be a solution to barriers in all the other areas. In fact, all of the participating experts in all areas agreed that despite the fast evolution of IT, there is a core of basic concepts of health IT and biomedical computing that should be delivered to medical students, so that they become "educated users". To the designers and developers, the educational pathway of Biomedical/Healthcare engineering looks promising to minimize the barriers. Interestingly, these experts also indicated that there are some barriers concerning the lack of education of health managers, which should include the study of process-based approaches and a more robust training in project design and development specifically for healthcare.

Research in the field of Clinical Communication should be reinforced over the next few years. Our results highlighted the problem of information sharing among different user profiles for the first time. While that problem goes beyond the adoption of standards, its solution requires the development of domain vocabularies, or even ontologies to support the needs for the healthcare processes (such as transmitting, reusing and sharing patient data; and providing semantic-based criteria to sustain different statistical aggregations for different purposes). Ontologies can help firstly by building more powerful and more interoperable information systems in healthcare, and secondly by maintaining semantic interoperability of patient data in a continuity of care scenario. Despite the development of ontologies for medicine, there are at present no query languages ready for semantic inquiring.

Because our approach was based on the operating experiences of experts in the Italian EHR scenarios, the barriers we highlighted are specific to Italy. The approach we took considered the working areas of healthcare where data are digitally generated, used, managed, and shared, and involved experts from these areas in a Delphi-like procedure. This methodology could also be successfully applied to other fields characterized by multiple stakeholders with different roles and views that need to be reconciled to manage uncertainties [16].

\section{CONCLUSIONS}

In conclusion, our work proposes a novel pragmatic framework for the evaluation of the barriers against EHR adoption and use in the Italian experience. We proposed future perspectives to be put into practice in designing solutions. Such design should be in line with the environment of the operating area where the barriers arose. In diagnostic services, short term solutions can be achieved through the enhancement of interoperability among systems, also beyond standard adoption. Development of more 
reliable systems capable of representing and integrating complex data as well as managing processes based on clinical guidelines is recommended to lower risks of medical errors in Hospital Wards. Systems for efficacious information exchange between heterogeneous providers are recommended for territorial healthcare. The introduction of process-based modeling tools in hospital management is a possible solution for cutting costs related to management and organization in the hospital environment. Educational weaknesses are perceived as a very severe barrier. Educational empowerment aimed at reducing the gap between the "users" and the "developers" of health information systems is the primary long-term solution to alleviate barriers spreading to all the other areas. Finally, the development of domain vocabularies, or even medical ontologies, would benefit the transmission, re-use and sharing of patient data in healthcare processes, and would provide semantic-based criteria to sustain different statistical aggregations for different purposes.

\section{CONFLICT OF INTEREST:}

The authors indicated no potential conflicts of interest.

\section{REFERENCES}

[1] Peterson HE. From Punched Cards to Computerized Patient Records: a Personal Journey, in: Reinhold Haux and Casimir Kulikowsky (eds). Assessing Information Technologies for Health. Yearbook of Medical Informatics, Schattauer Verlagsgesellschaft mbH, Stuttgart, D, 2006, 180-186.

[2] Ludwick DA, Doucette J. Adopting Electronic Medical Records in Primary Care: Lessons Learned from Health Information Systems Implementation Experience in Seven Countries. International Journal of Medical Informatics, 2009, 78(1), 22-31.

[3] International Organization for Standardization. ISO/DTR 20514: 2005. Health Informatics Electronic Health Record - Definition, Scope, and Context. 2005.

[4] Häyrinen K, Saranto K, Nykänen P. Definition, Structure, Content, Use and Impacts of Electronic Health Records: a Review of the Research Literature. International Journal of Medical Informatics, 2008, 77(5), 291-304.

[5] Kalra D. Electronic Health Record Standards, in: Reinhold Haux and Casimir Kulikowsky (eds). Assessing Information Technologies for Health. Yearbook of Medical Informatics, Schattauer Verlagsgesellschaft mbH, Stuttgart, D, 2006, 136-144.

[6] Nøhr C. Evaluation of Electronic Health Record Systems, in: Reinhold Haux and Casimir Kulikowsky (eds). Assessing Information Technologies for Health. Yearbook of Medical Informatics, Schattauer Verlagsgesellschaft mbH, Stuttgart, D, 2006, 107-113.

[7] Garg AX, Adhikari NK, McDonald H, Rosas-Arellano MP, Devereaux PJ, Beyene J, Sam J, Haynes RB. Effects of Computerized Clinical Decision Support Systems on Practitioner Performance and Patient Outcomes: a Systematic Review. JAMA: the Journal of the American Medical Association, 2005, 293(10), 1223-1238.

[8] Gryfe CI. Getting Physicians to Accept New Information Technology. Canadian Medical Association Journal, 2006, 174(11), 1573-1578.

[9] Doebbeling BN, Chou AF, Tierney WM. Priorities and Strategies for the Implementation of Integrated Informatics and Communications Technology to Improve Evidence-Based Practice. Journal of General Internal Medicine, 2006, 21 (Suppl 2), S50-S57.

[10] Ash JS, Berg M, Coiera E. Some Unintended Consequences of Information Technology in Health Care: the Nature of Patient Care Information System-related Errors. Journal of the American Medical Informatics Association, 2004, 11(2), 104-112. 
[11] School of Management of the Politecnico di Milano. Dipartimento di Ingegneria Gestionale. ICT in Sanità: l'Innovazione dalla Teoria alla Pratica - Rapporto 2009, Osservatorio ICT in Sanità, IT, July 2009. [In Italian].

[12] Greenhalgh T, Potts HWW, Wong G, Bark P, Swinglehurst D. Tensions and Paradoxes in Electronic Patient Record Research: A Systematic Literature Review Using the Meta-Narrative Method. The Milbank Quarterly, 2009, 87(4), 729-788.

[13] Car J, Black A, Anandan C, Cresswell K, Pagliari C, McKinstry B, Procter R, Majeed A, Sheikh A. The Impact of eHealth on the Quality \& Safety of Healthcare: A Systemic Overview \& Synthesis of the Literature. Birmingham: NHS Connecting for Health Evaluation Programme. 2008. Available at http://www.haps.bham.ac.uk/ publichealth/cfhep/documents/ NHS_CFHEP_001_Final_Report. pdf. Accessed June 5, 2010.

[14] Shekelle PG, Goldzweig CL. Costs and Benefits of Health Information Technology: An Updated Systematic Review. Health Foundation for Southern California Evidence-Based Practice Center, RAND Corporation, CA, 2009.

[15] Robert G, Greenhalgh T, MacFarlane F, Peacock R. Adopting and Assimilating New NonPharmaceutical Technologies into Health Care: a Systematic Review. Journal of Health Services Research and Policy, 2010, 15(4), 243-250.

[16] Aspinall W. A Route to more Tractable Expert Advice. Nature, 2010, 463, 294-295.

[17] Rowe G, Wright G. The Delphi Technique as a Forecasting Tool: Issues and Analysis. International Journal of Forecasting, 1999, 15(4), 353-375.

[18] Stream GR. Trends in Adoption of Electronic Health Records by Family Physicians in Washington State. Informatics in Primary Care, 2009, 17(3), 145-152.

[19] Hoerbst A, Kohl CD, Knaup P, Ammenwerth E. Attitudes and Behaviors Related to the Introduction of Electronic Health Records Among Austrian and German Citizens. International Journal of Medical Informatics, 2010, 79(2), 81-89.

[20] Doyle MJ. Open Source will Help Drive EHR Costs Down. The Use of Open Source in Healthcare Will Break Down Many Barriers, from High Cost and Lack of Interoperability, to Inaccessibility and Complexity. Health Management Technology, 2009, 30(9), 10-11.

[21] Middleton B. The Clinical Decision Support Consortium. Studies in Health Technology and Informatics, 2009, 150, 26-30.

[22] Whittaker AA, Aufdenkamp M, Tinley S. Barriers and Facilitators to Electronic Documentation in a Rural Hospital. Journal of Nursing Scholarship: an official publication of Sigma Theta Tau International Honor Society of Nursing, 2009, 41(3), 293-300.

[23] Terry AL, Giles G, Brown JB, Thind A, Stewart M. Adoption of Electronic Medical Records in Family Practice: the Providers' Perspective. Family Medicine, 2009, 41(7), 508-512.

[24] Kaushal R, Bates DW, Jenter CA, Mills SA, Volk LA, Burdick E, Tripathi M, Simon SR. Imminent Adopters of Electronic Health Records in Ambulatory Care. Informatics in Primary Care, 2009, 17(1), $7-15$.

[25] Walji MF, Taylor D, Langabeer JR 2nd, Valenza JA. Factors Influencing Implementation and Outcomes of a Dental Electronic Patient Record System. Journal of Dental Education, 2009, 73(5), 589-600.

[26] Burdyny C, Findlater S, Caron MP, Ajaz M. Strategies to Increase Familiarization and Acceptance of Electronic Health Records Among Health Professionals and Consumers. Studies in Health Technology and Informatics, 2009;143, 419-425.

[27] Meade B, Buckley D, Boland M. What Factors Affect the Use of Electronic Patient Records by Irish GPs? International Journal of Medical Informatics, 2009, 78(8), 551-558.

[28] Jha AK, DesRoches CM, Campbell EG, Donelan K, Rao SR, Ferris TG, Shields A, Rosenbaum S, Blumenthal D. Use of Electronic Health Records in U.S. Hospitals. The New England Journal of Medicine, 2009, 360(16), 1628-1638.

[29] Ross S. Results of a Survey of an Online Physician Community Regarding Use of Electronic Medical Records in Office Practices. The Journal of Medical Practice Management. 2009, 4(4), 254-256. 
[30] Balfour DC 3rd, Evans S, Januska J, Lee HY, Lewis SJ, Nolan SR, Noga M, Stemple C, Thapar K. Health Information Technology-Results from a Roundtable Discussion. Journal of Managed Care Pharmacy, 2009, 15(1 Suppl A), 10-17.

[31] Mostashari F, Tripathi M, Kendall M. A Tale of Two Large Community Electronic Health Record Extension Projects. Health Affairs (Millwood), 2009, 28(2), 345-356.

[32] Lorenzi NM, Kouroubali A, Detmer DE, Bloomrosen M. How to Successfully Select and Implement Electronic Health Records (EHR) in Small Ambulatory Practice Settings. BMC Medical Informatics and Decision Making, 2009, 9, 15.

[33] Yoon-Flannery K, Zandieh SO, Kuperman GJ, Langsam DJ, Hyman D, Kaushal R. A Qualitative Analysis of an Electronic Health Record (EHR) Implementation in an Academic Ambulatory Setting. Informatics in Primary Care, 2008, 16(4), 277-284.

[34] Menachemi N, Brooks RG, Schwalenstocker E, Simpson L. Use of health information technology by children's hospitals in the United States. Pediatrics, 2009,123 (Suppl 2):S80-S84.

[35] Ludwick DA, Doucette J. Primary Care Physicians' Experience with Electronic Medical Records: Barriers to Implementation in a Fee-for-Service Environment. International Journal of Telemedicine and Applications, 2009, 2009, 853524.

[36] Goroll AH, Simon SR, Tripathi M, Ascenzo C, Bates DW. Community-wide Implementation of Health Information Technology: the Massachusetts eHealth Collaborative Experience. Journal of the American Medical Informatics Association, 2009, 16(1), 132-139.

[37] Jha AK, Bates DW, Jenter C, Orav EJ, Zheng J, Cleary P, Simon SR. Electronic Health Records: Use, Barriers and Satisfaction Among Physicians Who Care for Black and Hispanic Patients. Journal of Evaluation in Clinical Practice, 2009, 15(1), 158-163.

[38] Kleaveland B. Making it to the EHR Promised Land. How to Solve Common EHR Adoption Problems. MGMA Connexion/ Medical Group Management Association, 2008, 8(5), 42-45, 1.

[39] DesRoches CM, Campbell EG, Rao SR, Donelan K, Ferris TG, Jha A, Kaushal R, Levy DE, Rosenbaum S, Shields AE, Blumenthal D. Electronic Health Records in Ambulatory Care-a National Survey of Physicians. The New England Journal of Medicine, 2008, 359(1), 50-60.

[40] Mechanic D. Rethinking Medical Professionalism: the Role of Information Technology and Practice Innovations. The Milbank Quarterly, 2008, 86(2), 327-358.

[41] Houser SH, Johnson LA. Perceptions Regarding Electronic Health Record Implementation Among Health Information Management Professionals in Alabama: a Statewide Survey and Analysis. Perspectives in Health Information Management, 2008, 5, 6.

[42] Marchibroda JM. The Impact of Health Information Technology on Collaborative Chronic Care Management. Journal of Managed Care Pharmacy, 2008, 14(2 Suppl), S3-S11.

[43] Bahensky JA, Jaana M, Ward MM. Health Care Information Technology in Rural America: Electronic Medical Record Adoption Status in Meeting the National Agenda. The Journal of Rural Health, 2008, 24(2), 101-105.

[44] Simon SR, McCarthy ML, Kaushal R, Jenter CA, Volk LA, Poon EG, Yee KC, Orav EJ, Williams DH, Bates DW. Electronic Health Records: Which Practices Have Them, and How Are Clinicians Using Them? Journal of Evaluation in Clinical Practice, 2008 Feb;14(1):43-7.

[45] Thakkar M, Davis DC. Risks, Barriers, and Benefits of EHR Systems: a Comparative Study Based on Size of Hospital. Perspectives in Health Information Management, 2006, 3, 5.

[46] Mehta NB, Partin MH. Electronic Health Records: a Primer for Practicing Physicians. Cleveland Clinic Journal of Medicine, 2007, 74(11), 826-830.

[47] Whitten P, Buis L, Mackert M. Factors Impacting Providers' Perceptions Regarding a Midwestern University-based EMR. Telemedicine Journal and e-Health, 2007, 13(4), 391-397.

[48] Mattocks K, Lalime K, Tate JP, Giannotti TE, Carr K, Carrabba A, Blum T, Meehan TP. The State of Physician Office-Based Health Information Technology in Connecticut: Current Use, Barriers and Future Plans. Connecticut Medicine, 2007, 71(1), 27-31. 
[49] Simon SR, Kaushal R, Cleary PD, Jenter CA, Volk LA, Poon EG, Orav EJ, Lo HG, Williams DH, Bates DW. Correlates of Electronic Health Record Adoption in Office Practices: a Statewide Survey. Journal of the American Medical Informatics Association, 2007, 14(1), 110-117.

[50] Anderson JG. Social, Ethical and Legal Barriers to e-Health. International Journal of Medical Informatics, 2007, 76(5-6), 480-483.

[51] Harrison JP, Palacio C. The Role of Clinical Information Systems in Health Care Quality Improvement. The Health Care Manager, 2006, 25(3), 206-212.

[52] Menachemi N, Perkins RM, van Durme DJ, Brooks RG. Examining the Adoption of Electronic Health Records and Personal Digital Assistants by Family Physicians in Florida. Informatics in Primary Care, 2006, 14(1), 1-9.

[53] Nelson R. Connecting the Providers in Your Healthcare Community: One Step at a Time. Frontiers of Health Services Management, 2005, 22(2), 13-28.

[54] Poon EG, Jha AK, Christino M, Honour MM, Fernandopulle R, Middleton B, Newhouse J, Leape L, Bates DW, Blumenthal D, Kaushal R. Assessing the Level of Healthcare Information Technology Adoption in the United States: a Snapshot. BMC Medical Informatics and Decision Making, 2006, 6, 1.

[55] Ford EW, Menachemi N, Phillips MT. Predicting the Adoption of Electronic Health Records by Physicians: When Will Health Care Be Paperless? Journal of the American Medical Informatics Association, 2006, 13(1), 106-112.

[56] Bates DW. Physicians and Ambulatory Electronic Health Records. Health Affairs (Millwood), 2005, 24(5), 1180-1189.

[57] Audet AM, Doty MM, Peugh J, Shamasdin J, Zapert K, Schoenbaum S. Information Technologies: When Will They Make it into Physicians' Black Bags? MedGenMed: Medscape General Medicine, 2004, 6(4), 2.

[58] Berner ES, Detmer DE, Simborg D. Will the Wave Finally Break? A Brief View of the Adoption of Electronic Medical Records in the United States. Journal of the American Medical Informatics Association, 2005, 12(1), 3-7.

[59] Sprague L. Electronic health records: How Close? How Far to Go? National Health Policy Forum Issue Brief, 2004, (800), 1-17.

[60] Terry NP. Electronic Health Records: International, Structural and Legal Perspectives. Journal of Law and Medicine, 2004, 12(1), 26-39.

[61] Valdes I, Kibbe DC, Tolleson G, Kunik ME, Petersen LA. Barriers to Proliferation of Electronic Medical Records. Informatics in Primary Care, 2004, 12(1), 3-9.

[62] Miller RH, Sim I. Physicians' Use of Electronic Medical Records: Barriers and Solutions. Health Affairs (Millwood), 2004, 23(2), 116-126.

[63] Bates DW, Ebell M, Gotlieb E, Zapp J, Mullins HC. A Proposal for Electronic Medical Records in U.S. Primary Care. Journal of the American Medical Informatics Association, 2003, 10(1), 1-10.

[64] Cawdron R, Calder J, Issenman RM. e-Health? Clinical Information Network Interest and Impediments in a Community Paediatric Setting. Paediatrics \& Child Health, 2001,6(10), 762-766.

[65] Safran C, Goldberg H. Electronic Patient Records and the Impact of the Internet. International Journal of Medical Informatics, 2000, 60(2), 77-83.

[66] Stanberry B. Telemedicine: Barriers and Opportunities in The 21st Century. Journal of Internal Medicine, 2000, 247(6), 615-628.

[67] Lazarus SS. Physicians' Use of Electronic Medical Records-Identifying and Crossing the Barriers. Medical Group Management Journal, 1999, 46(3), 12-14.

[68] Apkon M, Singhaviranon P. Impact of an Electronic Information System on Physician Workflow and Data Collection in the Intensive Care Unit. Intensive Care Medicine, 2001, 27(1), 122-130.

[69] Katehakis DG, Stelios Halkiotis S, Kouroubali A. Materialization of Regional Health Information Networks in Greece: Electronic Health Record Barriers \& Enablers. Journal of Healthcare Engineering, 2011, 2(3), 389-403. 


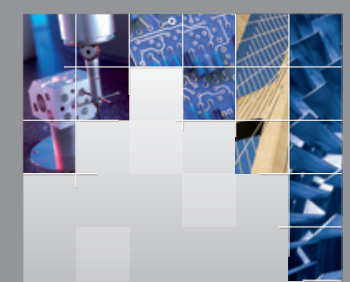

\section{Enfincering}
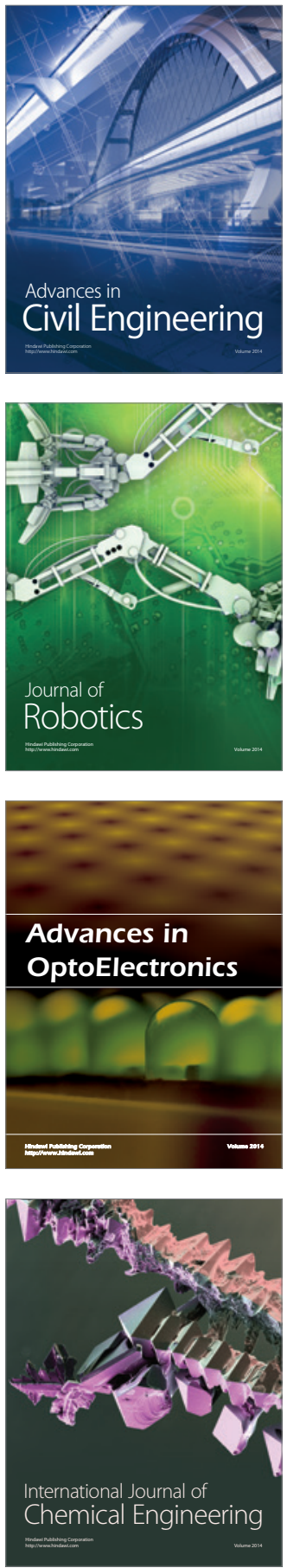

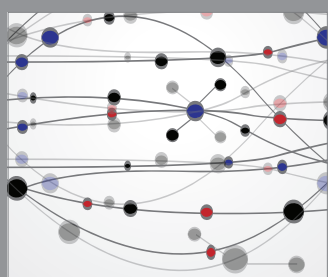

The Scientific World Journal

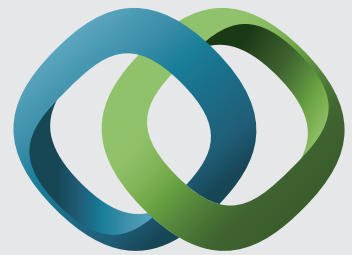

\section{Hindawi}

Submit your manuscripts at

http://www.hindawi.com
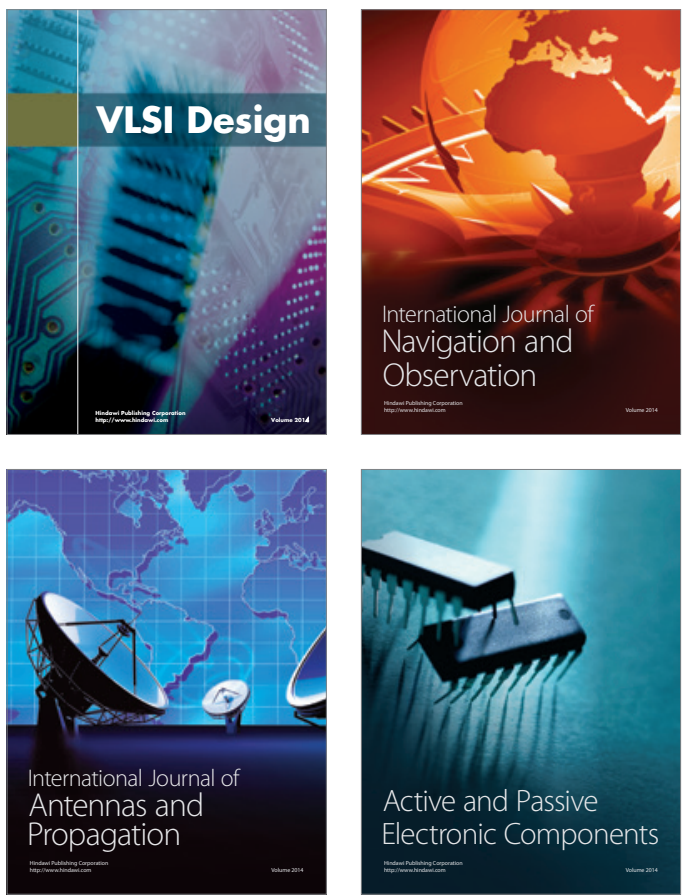
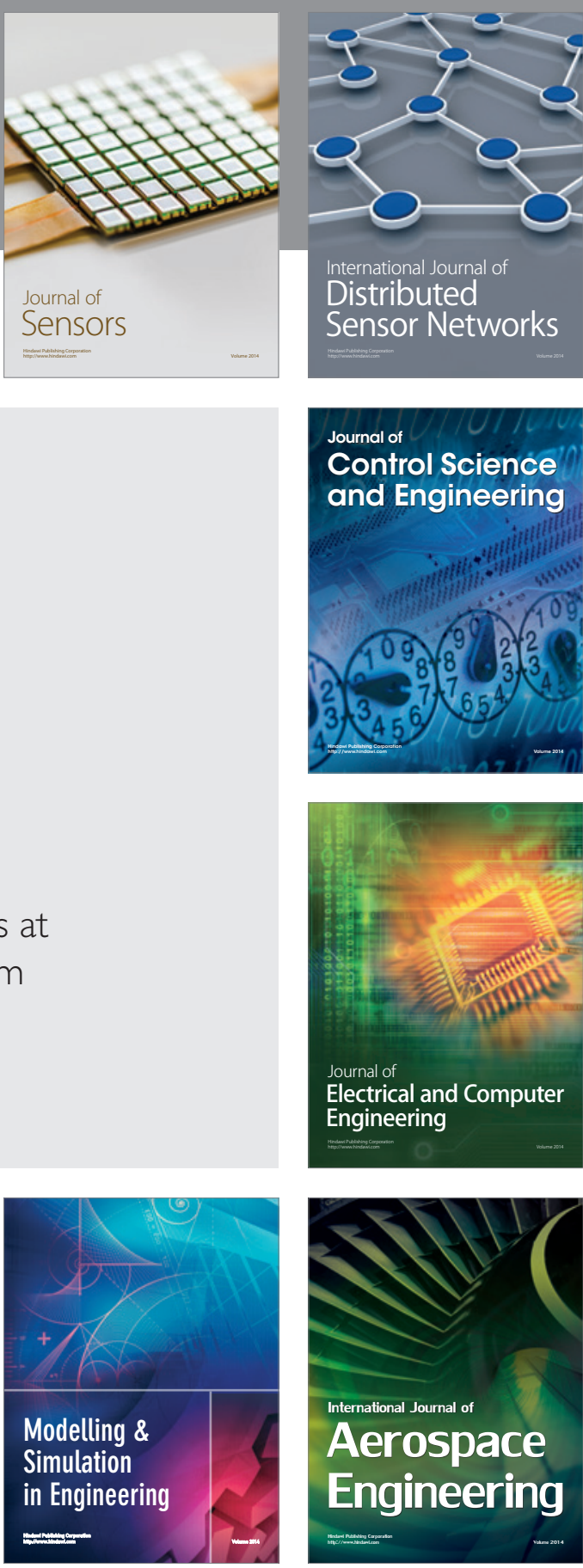

International Journal of

Distributed

Sensor Networks

Journal of

Control Science

and Engineering
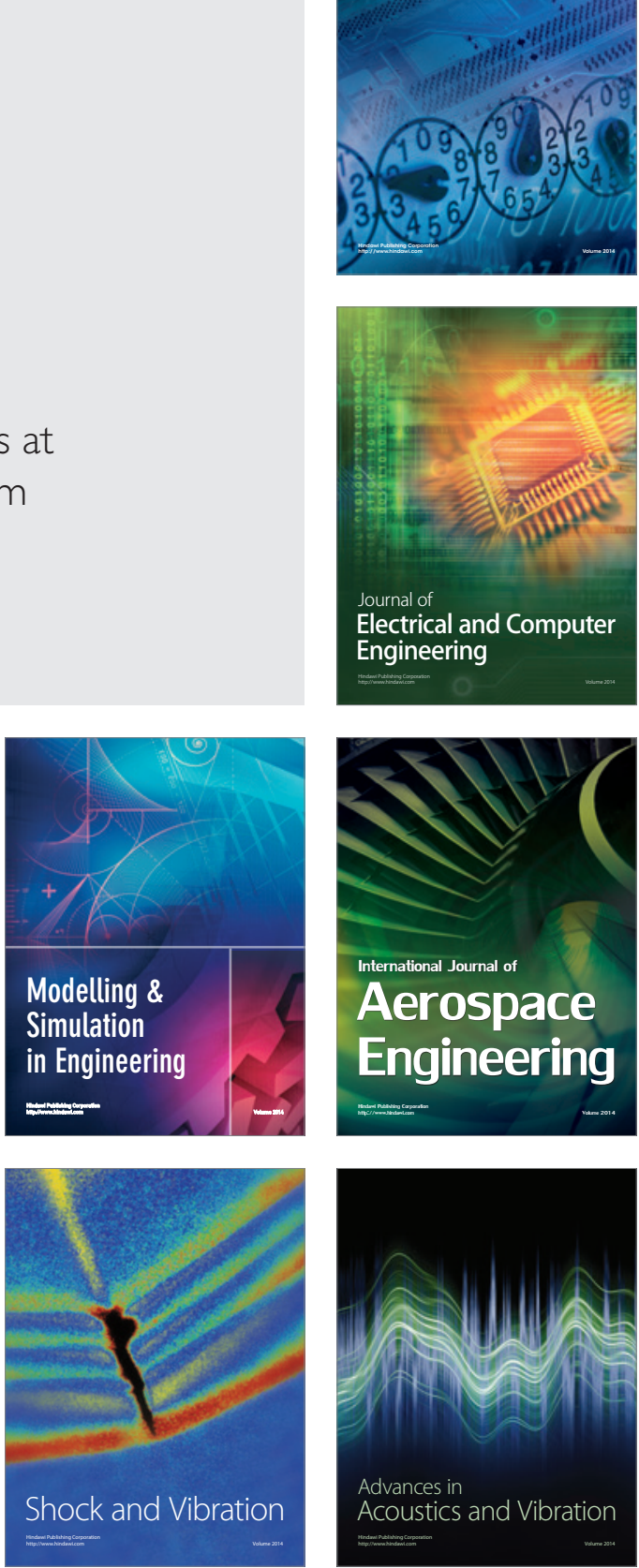